\title{
Effects of copper and aluminum on the adsorption of sulfathiazole and tylosin on peat and soil
}

\author{
Zhiguo Pei ${ }^{\mathrm{a}, *}$, Shuang Yang ${ }^{\mathrm{a}}$, Lingyun $\mathrm{Li}^{\mathrm{b}}$, Chunmei Li ${ }^{\mathrm{a}}$, Shuzhen Zhang ${ }^{\mathrm{a}}$, \\ Xiao-quan Shan ${ }^{a}$, Bei Wen ${ }^{\text {a }}$, Baoyuan Guo ${ }^{a}$ \\ a State Key Laboratory of Environmental Chemistry and Ecotoxicology, Research Center for Eco-Environmental Sciences, Chinese Academy of Sciences, \\ PO Box 2871, Beijing 100085, China \\ ${ }^{\mathrm{b}}$ Supervision and Testing Center for Vegetable Quality, Ministry of Agriculture, The Institute of Vegetables and Flowers, Chinese Academy of Agricultural \\ Sciences, Beijing, China
}

\section{A R T I C L E I N F O}

\section{Article history:}

Received 30 May 2013

Received in revised form

18 September 2013

Accepted 20 September 2013

\section{Keywords:}

Adsorption

Copper

Aluminum

Sulfathiazole

Tylosin

\begin{abstract}
A B S T R A C T
Effects of copper $(\mathrm{Cu})$ and aluminum $(\mathrm{Al})$ on the adsorption of sulfathiazole $(\mathrm{STZ})$ and tylosin $(\mathrm{T})$ to peat and soil were investigated using a batch equilibration method. Results show that Cu suppressed STZ adsorption onto peat and soil at $\mathrm{pH}<5.0$ because of the electrostatic competition, while increased STZ adsorption at $\mathrm{pH}>5.0$ due to the formation of STZ-Cu complexes and/or Cu bridge. In contrast, $\mathrm{Al}$ only decreased $\mathrm{STZ}$ adsorption at $\mathrm{pH}<6.0$, and exerted slight effect on $\mathrm{STZ}$ adsorption at $>6.0$. As for $\mathrm{T}$, both $\mathrm{Cu}$ and $\mathrm{Al}$ suppressed its adsorption over the entire $\mathrm{pH}$ range owing to three reasons: 1 ) electrostatic competition between $\mathrm{Cu} / \mathrm{Al}$ and $\mathrm{T}^{+} ; 2$ ) $\mathrm{Cu} / \mathrm{Al}$ adsorption made the soil and peat surface less negatively charged, which was unfavorable for $\mathrm{T}^{+}$adsorption; 3 ) the shrunken pore size of peat and soil retarded the diffusion of large-sized $\mathrm{T}$ into these pores.
\end{abstract}

() 2013 Elsevier Ltd. All rights reserved.

\section{Introduction}

Pharmaceutical antibiotics are widely used to treat diseases of human and animals or incorporated into animal feeds to improve growth rate and feed efficiency. However, these antibiotics are often poorly metabolized and absorbed by humans and animals, with most leaving the treated agents unmodified and consequently entering the environment (Sarmah et al., 2006). Removal of antibiotics by conventional water treatment technologies is incomplete (Zoritaa et al., 2009). A considerable portion of antibiotics can reach the soil environment through application of fertilizers, sewage sludge, wastewater irrigation, or the discarding of out-of-date pharmaceutical prescriptions (Golet et al., 2002). Exposures to residues of antibiotics and their transformed products might cause a variety of adverse consequences, including acute and chronic toxicity, and microorganism antibiotic resistance, etc (Schmitt et al., 2006). Adsorption of antibiotics to soils and sediments is an important process and influences their fate and transport in the environment. Currently, more concern is being paid to illustrate the environmental behavior and risks of antibiotics. Previous studies

\footnotetext{
* Corresponding author.

E-mail address: peizg@rcees.ac.cn (Z. Pei).
}

examined $\mathrm{pH}$-dependent adsorption of antibiotics onto clays (Heberer, 2002), aluminum oxides (Zoritaa et al., 2009; Golet et al., 2002; Gu and Karthikeyan, 2005), amorphous iron oxides (Zoritaa et al., 2009), goethite (Golet et al., 2002), soil and soil minerals (Kolpin et al., 2002; Nowara et al., 1997), and carbon nanotubes (Wang et al., 2010). In addition to hydrophobic partitioning, antibiotics may be adsorbed via cation exchange and cation bridging (Trivedi and Vasudevan, 2007), surface complexation (Zoritaa et al., 2009; Golet et al., 2002), salting out effects (Zhou, 2006), and hydrogen bonding (Tolls, 2001).

The coexistence of heavy metals and antibiotics is common in the environment (Wang et al., 2008). Many antibiotics with various acidic or basic functional groups can complex with heavy metal ions in solution, which alter their individual speciation and consequent environmental behaviors (Pan et al., 2012). Compared to single solute system, studies on the mutual adsorption of antibiotics and metal ions on solid particles could significantly further improve our understanding of antibiotic risks (Pan et al., 2012). However, it should be noted that previous studies generally chose antibiotics with complexation ability as adsorbates, and mainly focused on the role of complexation reaction in the adsorption (Wang et al., 2008). In fact, there are many antibiotics with no complex ability or with complex ability only under certain $\mathrm{pH}$ condition (Tolls, 2001). How heavy metals affect these antibiotics 
adsorption on soil was unknown. In addition, it was reported that the presence of heavy metals could result in changes in soil properties and structure (Pei et al., 2011; Wang et al., 2007; Yuan and Xing, 2001). For example, it was found that heavy metals could decrease the negatively charged density on soil surfaces (Hou et al., 2007), and make humic acids and biopolymers more condensed and rigid (Wang et al., 2007). Heavy metals also promote the aggregation and precipitation of soil colloid in solution (Ugochukwu et al., 2011). It is therefore to be expected that these changes of soil properties and structures will consequently influence the adsorption of antibiotics to certain extent (Luo et al., 2008). However, as far as we know the question on how the changed characteristics of soil by heavy metals on the adsorption of antibiotics have not been appropriately addressed, and the underlying mechanisms are unknown.

In this study, we chose sulfathiazole (STZ) and tylosin (T) as common representative of antibiotics. STZ has two $\mathrm{p} K_{\mathrm{a}}(2.0$ and 7.24), and can exist either as $\mathrm{STZ}^{+}, \mathrm{STZ}^{0}$ or $\mathrm{STZ}^{-}$forms in aqueous solution at different $\mathrm{pH}$ conditions due to protonation and deprotonation (Fig. S1). The result of copper-ion-selective electrode experiment suggested that $\mathrm{STZ}^{-}$could form $\mathrm{Cu}-\mathrm{STZ}$ complexes with $\mathrm{Cu}$ using its deprotonated imino group through electrostatic attraction, while $\mathrm{STZ}^{+}$and $\mathrm{STZ}^{0}$ had very slight complex ability with $\mathrm{Cu}$ (Fig. S2). Thas one $\mathrm{p} K_{\mathrm{a}}$ (7.1), and can exist as $\mathrm{T}^{+}$at acidic $\mathrm{pH}$, and as $\mathrm{T}^{0}$ at basic $\mathrm{pH}$ (Fig. S1). Fig. $\mathrm{S} 2$ showed that both $\mathrm{T}^{+}$and $\mathrm{T}^{0}$ could not complex with $\mathrm{Cu}$. Cu was chosen due to wide use in animal feed as a growth promoter, while $\mathrm{Al}$ was one of the most frequent elements within the Earth's crust. In addition, different chemical species of $\mathrm{Cu}$ and $\mathrm{Al}$ at different $\mathrm{pH}$ help to explore the underlying adsorption mechanisms. The objectives of this study were (i) to reveal the effects of $\mathrm{Cu}$ and $\mathrm{Al}$ on the adsorption of STZ and $\mathrm{T}$ on peat and soil; and (ii) to elucidate the relevant mechanisms by exploring the interactions of metals and antibiotics in solution and in solution/adsorbent interface, which could be a useful approach to provide an insight into the mechanisms governing the adsorption in multi-solute systems.

\section{Materials and methods}

\subsection{Materials}

A black chernozem soil (a clay loam Mollisol) was collected from surface horizon $(0-20 \mathrm{~cm})$ in Heilongjiang Province, northeastern China. Soil was air-dried, ground, and homogenized to pass a $1.0 \mathrm{~mm}$ sieve. The peat sample was also collected from Heilongjiang Province and was dried at $105^{\circ} \mathrm{C}$, ground, and homogenized to pass through a $0.15 \mathrm{~mm}$ sieve. Nitrogen specific surface area (SSA) of peat and soil were measured using an accelerated surface area system by applying the BrunauerEmmet-Teller (BET) equation to adsorption of $\mathrm{N}_{2}$ at $77 \mathrm{~K}$. Other characteristics of peat and soil were determined by the methods of Nelson and Sommers (1996) and Sumner and Miller (1996), and the properties are listed in Table S1.

Two antibiotics, STZ and T (purity of $>98 \%$ ), were purchased from Aldrich Chemical Co. Inc. (Milwaukee, WI, USA) and the structures and properties are shown in Table $\mathrm{S} 2 . \mathrm{Cu}\left(\mathrm{NO}_{3}\right)_{2}, \mathrm{Al}\left(\mathrm{NO}_{3}\right)_{3}, \mathrm{NaNO}_{3}, \mathrm{NaOH}$, and $\mathrm{HNO}_{3}$ were all reagent grade chemicals and methanol was HPLC grade.

\subsection{Adsorption experiments}

STZ and T were dissolved in $0.01 \mathrm{M} \mathrm{NaNO}_{3}$ solution, to which $\mathrm{NaN}_{3}\left(0.1 \mathrm{~g} \mathrm{~L}^{-1}\right)$ was added to suppress the growth of bacteria. All adsorption experiments were conducted in triplicates using a batch equilibration technique at $23 \pm 1{ }^{\circ} \mathrm{C}$. Adsorption of STZ and T $(2.5,5.0,12.5,17.5,25.0$, and $37.5 \mathrm{mg} / \mathrm{L})$ were carried out by mixing a certain amount of peat and soil with $0.01 \mathrm{M} \mathrm{NaNO}_{3}$ solution in presence of $0,0.5$ and $1.0 \mathrm{mM} \mathrm{Cu}$ or $\mathrm{Al}$ in $50 \mathrm{~mL}$ glass centrifuge tubes sealed with Teflon-lined screw caps. The $\mathrm{pH}$ of the adsorbent suspension was adjusted to $6.0 \pm 0.1$ by dropwise addition of $0.1 \mathrm{M} \mathrm{HNO}_{3}$ or $\mathrm{NaOH}$. In order to maintain the final $\mathrm{pH}$ within experimental error, the suspension $\mathrm{pH}$ was readjusted every $2 \mathrm{~h}$ during the first $8 \mathrm{~h}$ of equilibration, subsequently the final $\mathrm{pH}$ was maintained within $\pm 0.1 \mathrm{pH}$ units. Under such conditions, STZ was present in solution as neutral and anionic forms, and $\mathrm{T}$ was in cationic form, respectively. Our previous experiments also indicated that coprecipitation of STZ or T with $\mathrm{Cu} / \mathrm{Al}$ was unlikely at $\mathrm{pH} 6.0$ (data not shown). The suspension was rotated continuously for $24 \mathrm{~h}$ for STZ and $72 \mathrm{~h}$ for $\mathrm{T}$ to ensure complete adsorption (apparent equilibrium was reached before this time). After centrifugation at $1667 \mathrm{~g}$ for $20 \mathrm{~min}$, the concentrations of STZ and T in the supernatant were determined by HPLC (Agilent 1200 HPLC). Controls were also prepared identically but contained no adsorbents, which were simultaneously run to assess loss of solutes. Results show that no significant loss of solutes was observed, indicating that microbial degradation, volatilization, or adsorption to the glass walls were negligible during the adsorption experiments.

At the end of adsorption experiments, aliquots of supernatant $(10 \mathrm{~mL})$ were withdrawn, the same volume of background desorption solution was added to replenish the adsorption suspension, after that the suspensions were shaken for $24 \mathrm{~h}$ for STZ and $72 \mathrm{~h}$ for T, then centrifuged, and the concentrations of STZ and T were analyzed. This procedure was repeated three cycles.

\subsection{Effect of $\mathrm{pH}$ on the adsorption of STZ and $T$}

The $\mathrm{pH}$ effect was conducted using a batch adsorption approach as mentioned above. Initial concentrations of both STZ and T were $12.5 \mathrm{mg} / \mathrm{L}$, and concentration of $\mathrm{Cu} / \mathrm{Al}$ was $1.0 \mathrm{mM}$, respectively. The $\mathrm{pH}$ was adjusted from 3.0 to 8.0 for peat and soil by addition of $0.1 \mathrm{M} \mathrm{HNO}_{3}$ or $\mathrm{NaOH}$. After equilibrium, the suspension was centrifuged at $1667 \mathrm{~g}$ for $20 \mathrm{~min}$ to separate the liquid and solid phases. The antibiotic and metal concentrations in the supernatant were determined by HPLC or ICP-AES (Plasma Quad3, Manchester, UK), respectively.

\subsection{Zeta potential (५) measurement}

The suspension for $\zeta$-potential measurements was prepared by mixing a certain amount of peat and soil with $0.01 \mathrm{M} \mathrm{NaNO}_{3}$ solution $(20 \mathrm{~mL})$ containing different concentrations of $\mathrm{Cu}$ or $\mathrm{Al}(0$ and $1.0 \mathrm{mM})$. The suspension was rotated continuously for $24 \mathrm{~h}$ at room temperature $\left(23 \pm 1{ }^{\circ} \mathrm{C}\right)$. The solution $\mathrm{pH}$ was adjusted to $3.0-7.0$ using $0.1 \mathrm{M} \mathrm{HNO}_{3}$ or $\mathrm{NaOH}$. The $\zeta$-potentials were measured on the basis of microelectrophoresis measurements on a Zetasizer 2000 (Malvern Instruments, U.K.). The voltage applied to the capillary cell was set at $150 \mathrm{~V}$ and the Henry function $[f(\mathrm{Ka})]$ of 1.5 was used to directly calculate $\zeta$-potentials. The electrophoretic capillary cell was rinsed three times with $50 \mathrm{~mL}$ of deionized water $(18 \mathrm{M} \Omega$ ) before each analysis. Five independent $\zeta$-potential measurements were collected for each sample to ensure accurate and reproducible data.

\subsection{Analysis}

STZ and T in the supernatants were determined by an Agilent 1200 reversedphase HPLC (Atlantis-dC 18 ODS HPLC column, 4.6 i.d. $\times 150 \mathrm{~mm}, 5 \mu \mathrm{m}$ ) equipped with UV detector. The determination wavelengths were set at $265 \mathrm{~nm}$ and $290 \mathrm{~nm}$ for STZ and T, respectively. The mobile phases were methol:water (30:70, v:v, pH 3.0 adjusted with acetic acid) for STZ, and methol:water (55:45, v:v, pH 3.0, adjusted with acetic acid) for $\mathrm{T}$ at a flow rate of $1.0 \mathrm{~mL} \mathrm{~min}^{-1}$. The concentrations of $\mathrm{Cu}$ and $\mathrm{Al}$ in the equilibrium solutions were determined by ICP-AES (Plasma Quad3, Manchester, UK). The adsorbed antibiotics and metals were calculated from the differences between the initial and final equilibrium concentrations.

\subsection{Data analysis}

Adsorption data were fitted to the Freundlich equation using software Origin 7.5, and nonlinear regression analyses were conducted by the least-squares method. Freundlich equation can be expressed as $Q=K_{\mathrm{f}} C^{n}$, where $Q(\mathrm{mg} / \mathrm{g})$ is the amount of adsorbed organic compounds by soil and peat, $C(\mathrm{mg} / \mathrm{L})$ is the equilibrium concentration in solution, $K_{\mathrm{f}}$ is an empirical constant related to adsorption capacity $\left(\mathrm{mg}^{(1-n)} \mathrm{g}^{-1} \mathrm{~L}^{n}\right)$, and $n$ is the Freundlich exponent or a site energy heterogeneity factor, often used as an indicator of isotherm nonlinearity.

\section{Results and discussion}

\subsection{Adsorption isotherms}

Fig. 1 shows the adsorption isotherms of STZ and Tat pH 6.0 on peat and soil in the absence and presence of $\mathrm{Cu}$ and $\mathrm{Al}$ ( 0.5 and $1.0 \mathrm{mM}$, respectively). The isotherms fitted Freundlich equation well, and are clearly nonlinear as characterized by low Freundlich parameter $n$ (Table S3).

As shown in Fig. 1a and b, the adsorption of STZ on peat and soil increased with increasing $\mathrm{Cu}$ concentrations from 0 to $1.0 \mathrm{mM}$, suggesting that $\mathrm{Cu}$ facilitated the adsorption of STZ. For example, the adsorption distribution coefficients $\left(K_{\mathrm{d}}\right)$ (initial concentration of $12.5 \mathrm{mg} / \mathrm{L}$ ) were used to compare the adsorption behavior of STZ (Table S3). Obviously, the $K_{\mathrm{d}}$ values increased from 0.1 to $0.27 \mathrm{~L} / \mathrm{g}$ for peat and 0.007 to $0.016 \mathrm{~L} / \mathrm{g}$ for soil when the $\mathrm{Cu}$ concentrations increased from 0 to $1.0 \mathrm{mM}$. In contrast, interestingly, the presence of Al had little effects on the adsorption of STZ on soil and even slightly decreased the adsorption of STZ on peat (Fig. 1a and b). The 
different effects of $\mathrm{Cu}$ and $\mathrm{Al}$ were likely to relate to their individual species in aqueous solution at $\mathrm{pH}$ 6.0, which would be explained in the following section.

Fig. 1c and d showed the adsorption isotherms of $\mathrm{T}$ on peat and soil in the presence and absence of $\mathrm{Cu} / \mathrm{Al}$. It was found that the adsorption of $\mathrm{T}$ decreased with the increase of $\mathrm{Cu} / \mathrm{Al}$ concentrations, suggesting the suppression effect of $\mathrm{Cu} / \mathrm{Al}$ on $\mathrm{T}$ adsorption. The $K_{\mathrm{d}}$ values (initial concentration of $12.5 \mathrm{mg} / \mathrm{L}$ ) were used to compare the effects of $\mathrm{Cu}$ and $\mathrm{Al}$ (Table S3). Obviously, the $K_{\mathrm{d}}$ values of T decreased from 0.68 to $0.26 \mathrm{~L} / \mathrm{g}$ on peat, and from 0.28 to $0.17 \mathrm{~L} /$ $\mathrm{g}$ on soil when the $\mathrm{Cu}$ or $\mathrm{Al}$ concentrations increased from 0 to $1.0 \mathrm{mM}$.

The Freundlich parameters (Table S3) suggest that the adsorption isotherm of STZ on peat and soil are nonlinear, with $n$ values 0.74 and 0.70 . This suggested that except for hydrophobic partitioning, pore-filling and/or some specific interactions with functional groups of soil organic matter and clay minerals were involved in adsorption (Thiele-Bruhn et al., 2004). Compared to the adsorption on soil, it is clearly shown that adsorption of STZ on peat was markedly stronger due to higher organic content in peat (Fig. $1 \mathrm{a}$ and b). Previous studies reported that sulfonamide antibiotics were preferred to be adsorbed to soil organic matter through site-specific hydrogen bonds and van der Waals interactions (Thiele-Bruhn et al., 2004; Kahle and Stamm, 2007). The adsorption isotherms of T on peat and soil are also nonlinear, with $n$ values 0.52 and 0.58 , indicating that some specific interactions were involved in adsorption. Different to STZ, soil with high clay content is also an effective adsorbent for T. This is likely because, except for hydrophobic interactions, cationic $\mathrm{T}$ also tended to be adsorbed on the negatively charged surface of peat and soil through electrostatic attraction, hydrogen or dipole bonding, etc (Kolz et al., 2005).

The adsorption of $\mathrm{Cu} / \mathrm{Al}$ on peat and soil as a function of $\mathrm{pH}$ with or without STZ or T are shown in Fig. S3. It was found that the adsorption of $\mathrm{Cu} / \mathrm{Al}$ on peat and soil increased with an increase of solution pH, consistent to previous references (Qin et al., 2004).
When STZ or T was added simultaneously, both STZ and T had little effect on the adsorption of $\mathrm{Cu} / \mathrm{Al}$, suggesting that $\mathrm{Cu} / \mathrm{Al}$ adsorption was independent of the presence of STZ and T.

\subsection{Effect of $p H$ on adsorption}

As shown in Fig. S1, STZ and T present at different species at different equilibrium solution pH. Fig. $2 \mathrm{a}$ and $\mathrm{b}$ shows the adsorption of STZ as a function of solution $\mathrm{pH}$ in the presence and absence of $\mathrm{Cu}$ and $\mathrm{Al}$. In the single solute system, it was found that the adsorption of STZ on peat and soil increased as solution $\mathrm{pH}$ decreased, consistent to the results of Boxall et al. (2002). Considering the $\mathrm{p} K_{\mathrm{a}}$ values of 2.0 and 7.24 for STZ, it appears that the greater adsorption of STZ at low pH may be attributed to the electrostatic attraction between $\mathrm{STZ}^{+}$and negatively charged peat and soil surface (Kahle and Stamm, 2007; Ter Laak et al., 2006). An increase of solution $\mathrm{pH}$ made the principal species of STZ from cationic form $\mathrm{STZ}^{+}$to neutral form $\mathrm{STZ}^{0}$ and anionic form $\mathrm{STZ}^{-}$ (Fig. S1), and the electrostatic repulsion between $\mathrm{STZ}^{-}$and the negatively charged peat and soil surface makes further adsorption unfavorable.

When $\mathrm{Cu}$ was present in solution, it was found that $\mathrm{Cu}$ suppressed the adsorption of STZ at $\mathrm{pH}<5.0$, but increased the adsorption of STZ significantly at $\mathrm{pH}>5.0$ on both peat and soil (Fig. 2a and b). As shown in Fig. S1, Cu was present as free $\mathrm{Cu}^{2+}$ in aqueous solution between $\mathrm{pH} 2.0$ and 5.0, the dominant species of STZ over this $\mathrm{pH}$ range were also cationic form $\mathrm{STZ}^{+}$and neutral form $\mathrm{STZ}^{0}$. Obviously, competition between positive charged $\mathrm{STZ}^{+}$ and $\mathrm{Cu}^{2+}$ for the same negatively charged adsorption sites on peat and soil was unfavorable for the adsorption of cationic $\mathrm{STZ}^{+}$at low $\mathrm{pH}$ range. When $\mathrm{pH}$ is higher than 5.0 , anionic form $\mathrm{STZ}^{-}$dominates, which may interact with $\mathrm{Cu}$ in solution (Fig. S2). Thus, anionic STZ could be adsorbed on peat and soil as $\mathrm{Cu}-\mathrm{STZ}$ complexes or through the formation of a $\mathrm{Cu}$ bridge, which enhanced STZ adsorption.
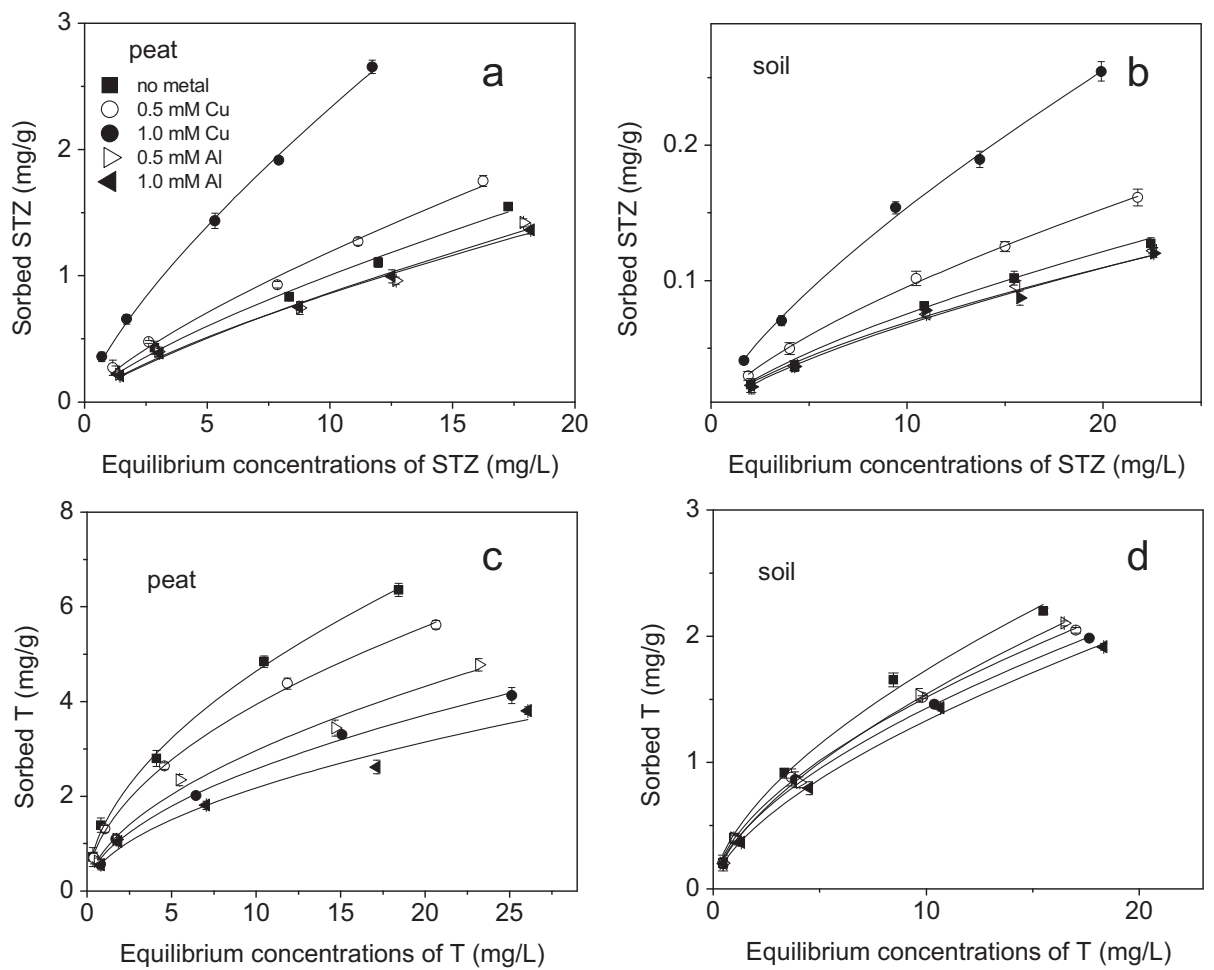

Fig. 1. Adsorption isotherms of $\mathrm{STZ}(\mathrm{a}, \mathrm{b})$ and $\mathrm{T}(\mathrm{c}, \mathrm{d})$ on peat and soil as affected by different concentrations of $\mathrm{Cu}$ and $\mathrm{Al}$ in $0.01 \mathrm{M} \mathrm{NaNO}_{3}$ solution at pH $6.0 \pm 0.1$. 

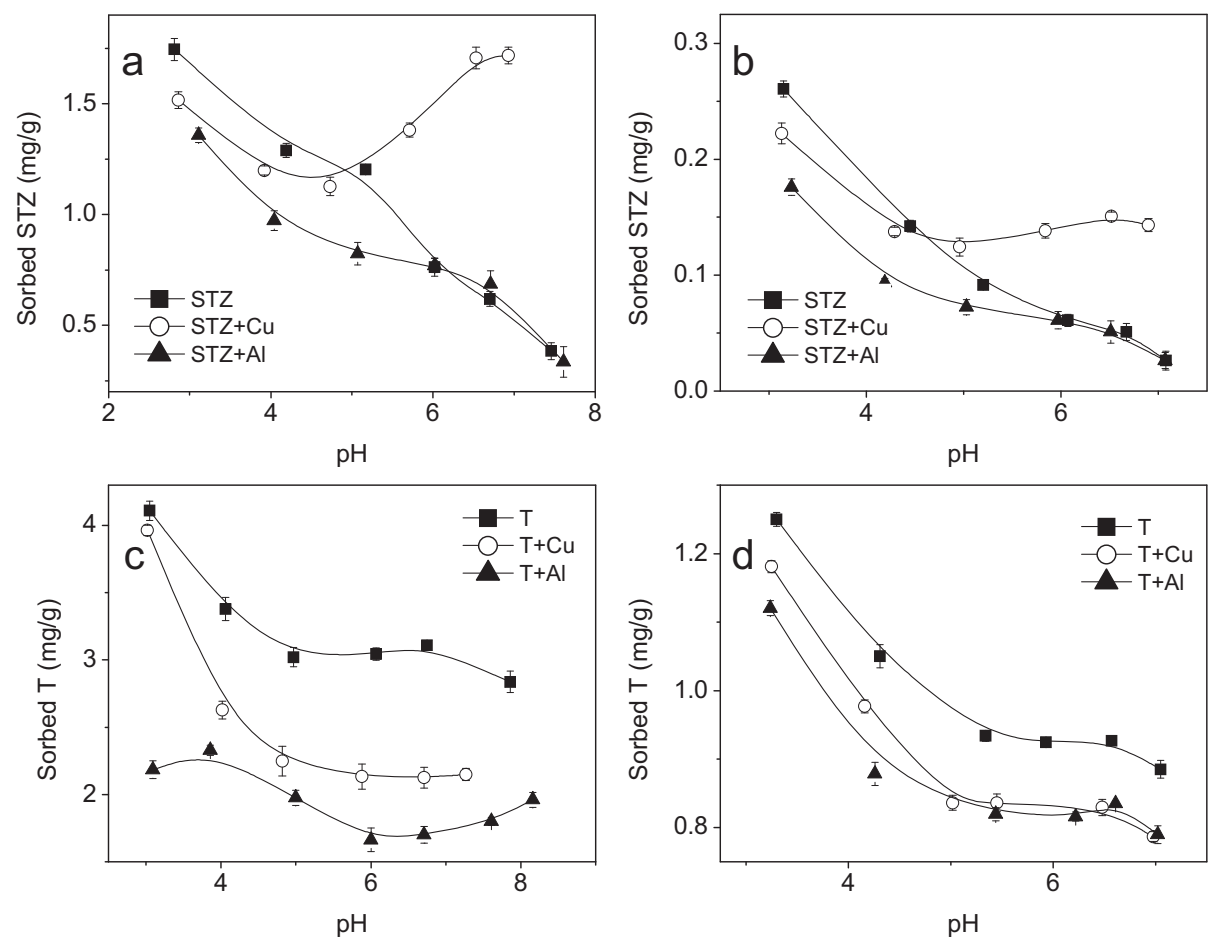

Fig. 2. Adsorption of $\mathrm{STZ}$ and $\mathrm{T}$ on peat $(\mathrm{a}, \mathrm{c})$ and soil $(\mathrm{b}, \mathrm{d})$ as a function of $\mathrm{pH}$ in the presence and absence of $1.0 \mathrm{mM} \mathrm{Cu}$ or $\mathrm{Al}$.

As shown in Fig. 2a and b, the addition of Al suppressed STZ adsorption at $\mathrm{pH}<6.0$; however, there was little effect on the adsorption of STZ at $\mathrm{pH}>6.0$. The different effects of $\mathrm{Cu}$ and $\mathrm{Al}$ on STZ adsorption were related to their individual chemical species in aqueous solution at different $\mathrm{pH}$ condition (Fig. S1). At $\mathrm{pH}<6.0$, cationic $\mathrm{Al}^{3+}, \mathrm{Al}(\mathrm{OH})^{2+}$ and $\mathrm{Al}(\mathrm{OH})_{2}^{+}$could interact with the permanent charge and variable charge sites on soil surface or the carboxyl and hydroxyl groups on soil organic matter, undoubtedly, which impeded $\mathrm{STZ}^{+}$adsorption via electrostatic attraction and $\mathrm{STZ}^{0}$ adsorption via $\mathrm{H}$-bonding and van der Waals interaction. At $\mathrm{pH}>6.0$, the prevailing species of $\mathrm{Al}$ were $\mathrm{Al}(\mathrm{OH})_{4}$ and a small amount of $\mathrm{Al}(\mathrm{OH})_{3}$ precipitate. It was significant that anionic $\mathrm{Al}(\mathrm{OH})_{4}^{-}$and $\mathrm{Al}(\mathrm{OH})_{3}$ precipitate could not interact with anionic $\mathrm{STZ}^{-}$, thus had little effect on $\mathrm{STZ}^{-}$adsorption on peat and soil.

As for $\mathrm{T}$, it was found that an increase in solution $\mathrm{pH}$ decreased the adsorption of $\mathrm{T}$ on peat and soil due to the decrease of electrostatic attraction (Ter Laak et al., 2006). When $\mathrm{T}$ and $\mathrm{Cu} / \mathrm{Al}$ were adsorbed simultaneously, the adsorbed $\mathrm{T}$ was always lower than that $\mathrm{T}$ was adsorbed alone over the examined $\mathrm{pH}$ range (Fig. $2 \mathrm{c}$ and d). Several possible mechanisms are be responsible for the suppressed adsorption of $\mathrm{T}$ in the presence of $\mathrm{Cu} / \mathrm{Al}$ are discussed below: (1) At low $\mathrm{pH}$ range, cationic $\mathrm{Cu} / \mathrm{Al}$ could compete with $\mathrm{T}^{+}$ for the same adsorption sites on peat and soil, and was unfavorable for the adsorption of $\mathrm{T}^{+}$. This reason was similar to the suppressed effect of $\mathrm{Cu} / \mathrm{Al}$ on $\mathrm{STZ}^{+}$adsorption. (2) The formation of surface complexes of cationic $\mathrm{Cu}$ and $\mathrm{Al}$ made the surfaces of both peat and soil less negatively charged (Fig. S4), leading to lower affinity for the adsorption of $\mathrm{T}^{+}$through electrostatic attraction. Compared to $\mathrm{Cu}$, Al has higher positive charge and can neutralize more negative charge from peat and soil. As a result, $\mathrm{Al}$ had a stronger suppression effect on Tadsorption than $\mathrm{Cu}$ (Fig. 2c and d). (3) The presence of $\mathrm{Cu}$ and $\mathrm{Al}$ aggregated and crosslinked the soil colloid phase in solution or solid organic matter of peat and soil, which could clog or shrink the pore size of peat and soil (Ugochukwu et al., 2011; Pei et al., 2006), thus made the diffusion of large-sized $T$ to these pores more difficult (Ji et al., 2010). Generally, soil pores played a crucial role in the adsorption of adsorbates, especially of large-sized adsorbates. Nakagawa et al. (2004) synthesized mesoporous activated carbon from solid wastes for adsorption of a bulky reactive dye, and attributed the relatively high adsorption capacity to pore-filling effect. In order to better elucidate the contribution of pore-filling effect in $\mathrm{T}$ adsorption, a kinetics study was conducted in the following section.

\subsection{Adsorption kinetics}

Fig. 3 compares the adsorption kinetics of STZ and T between peat and soil in the presence and absence of $\mathrm{Cu}$ and Al. For STZ, it was shown that adsorption equilibrium was reached within about $3 \mathrm{~h}$ on soil, and $10 \mathrm{~h}$ on peat, suggesting that the adsorption of STZ on soil is faster. The addition of $\mathrm{Cu}$ and $\mathrm{Al}$ had little effect on the adsorption kinetics of STZ on both adsorbents due to its small molecular size (Fig. 3a and b).

Unlike STZ with small sphere, $\mathrm{T}$ is a non-rigid molecule with bulky, flexible structure. Using the Gaussian 98 program (Frisch et al., 1998), we simulated the molecular structures of STZ and T, it was indicated that the molecular diameter of STZ is about $9.72 \AA$, while the molecular diameter of $\mathrm{T}$ is about $21.76 \AA$. Accordingly, it is expected that the change of soil pore size would play a role in the diffusion of $\mathrm{T}$ molecule within the pores of peat and soil. As shown in Fig. 3, adsorption of T reached equilibrium after about $3 \mathrm{~h}$ on soil, and about $10 \mathrm{~h}$ on peat. When $\mathrm{Cu}$ and $\mathrm{Al}$ were added, the equilibrium time of $\mathrm{T}$ adsorption onto soil increased to $20 \mathrm{~h}$, and to even $70 \mathrm{~h}$ for peat, suggesting that $\mathrm{Cu}$ and $\mathrm{Al}$ slowed the adsorption kinetics of T on peat and soil. Fig. S5 compares the soil morphology before and after $\mathrm{Cu}$ adsorption. It was significant that the presence of metal ion precipitated soil colloid in solution and overlaid them onto soil surface. As shown in Table S4, when peat and soil were treated with $1.0 \mathrm{mM} \mathrm{Cu}$ or Al solution, the average pore sizes of two adsorbents decreased from 149.8 and $89.5 \AA$ to 93.9 and $41.0 \AA$, respectively. The change in pore size was partially caused by the aggregation and precipitation of the colloidal phase in solution in 

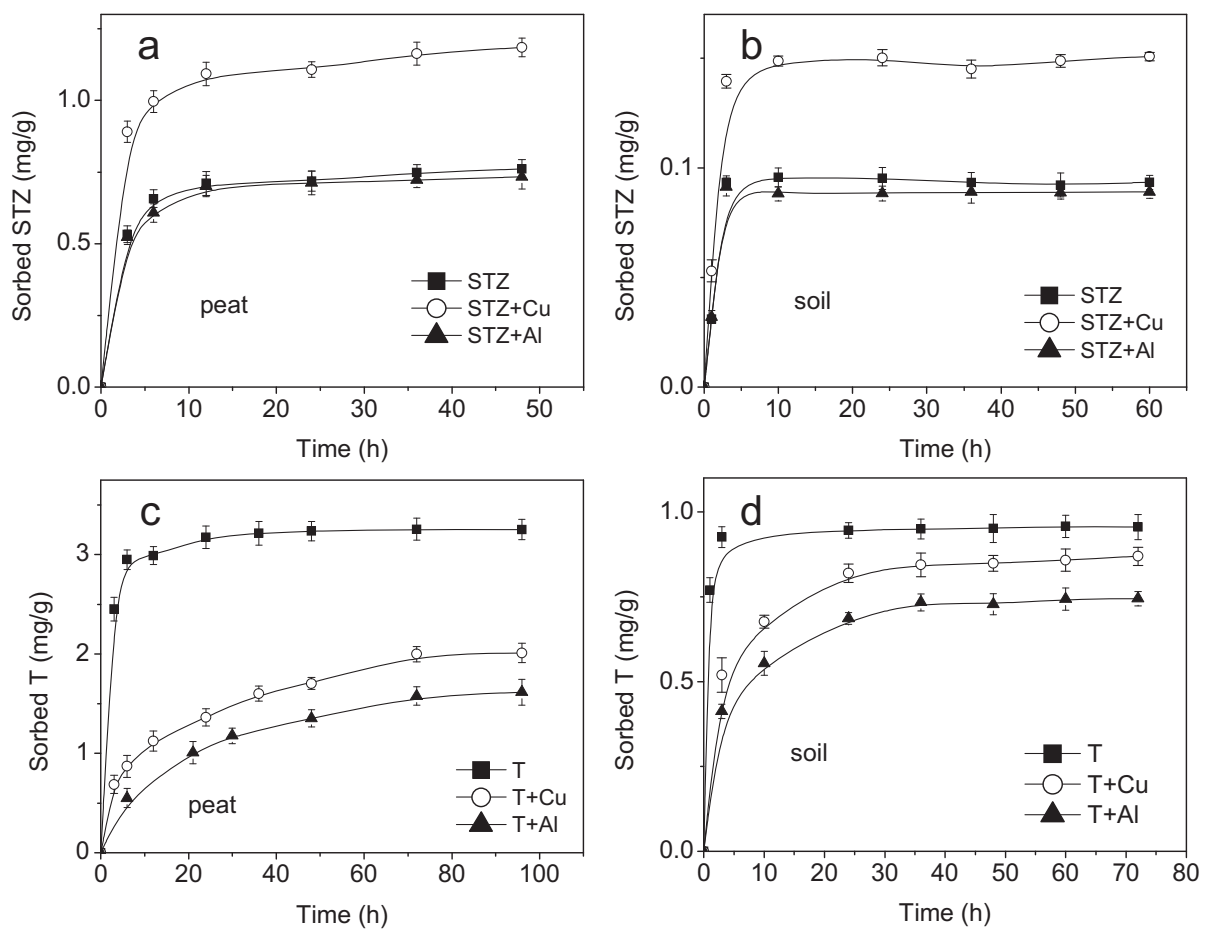

Fig. 3. Adsorption kinetics of $\mathrm{STZ}(\mathrm{a}, \mathrm{b})$ and $\mathrm{T}(\mathrm{c}, \mathrm{d})$ on peat and soil in the presence and absence of $1.0 \mathrm{mM} \mathrm{Cu} / \mathrm{Al}$.

the presence of polyvalent cations, which precipitated on peat and soil surface and blocked their pores correspondingly. Moreover, parts of flexible solid organic matter also tended to be condensed and became more rigid in the presence of polyvalent cations due to cation bridges with anionic functional groups of humic acids (Lu and Pignatello, 2004). As a result, diffusion of bulky, flexible $\mathrm{T}$ molecule within these shrunk pores of peat and soil became much slower than that in the absence of $\mathrm{Cu}$ or Al. This was evidenced by

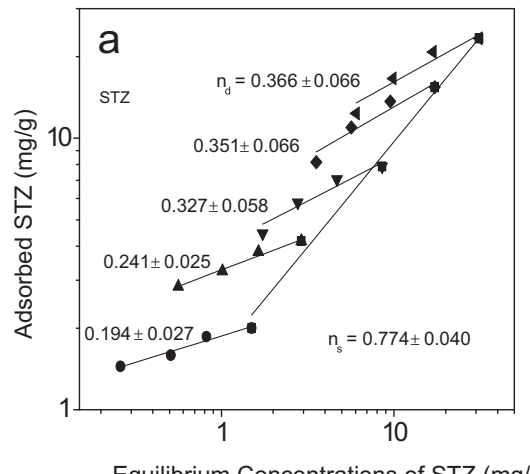

Equilibrium Concentrations of STZ (mg/L)
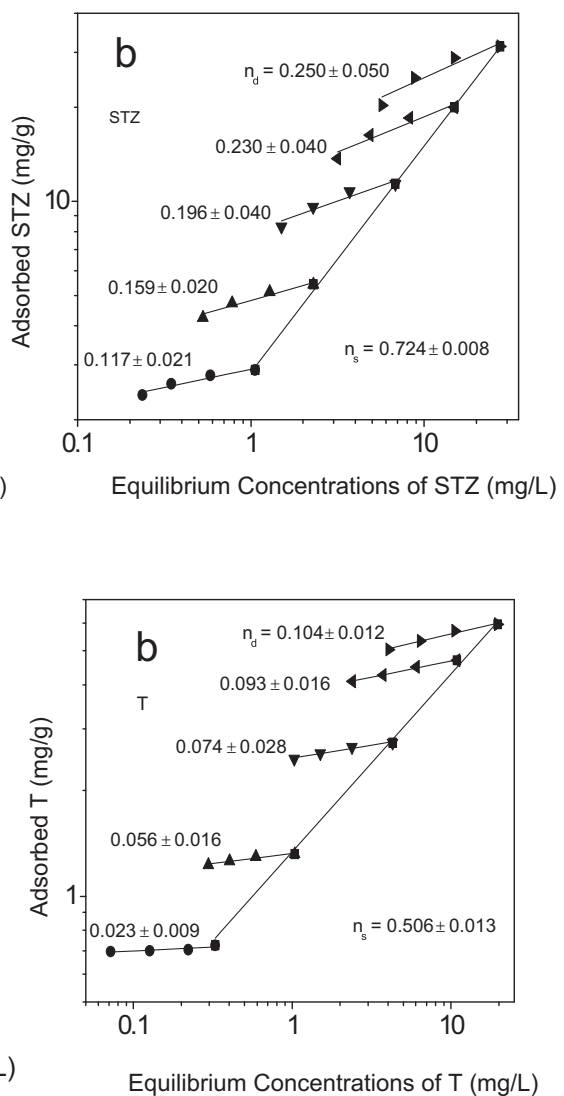

Equilibrium Concentrations of $\mathrm{T}(\mathrm{mg} / \mathrm{L})$

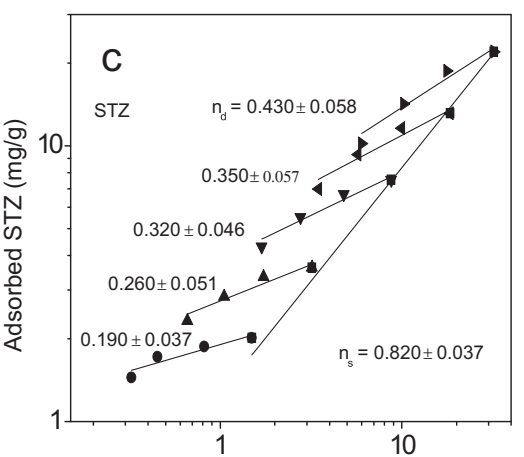

Equilibrium Concentrations of STZ (mg/L)

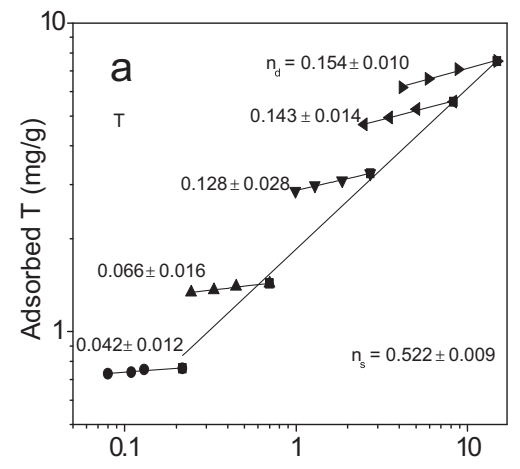

Equilibrium concentrations of $\mathrm{T}(\mathrm{mg} / \mathrm{L})$

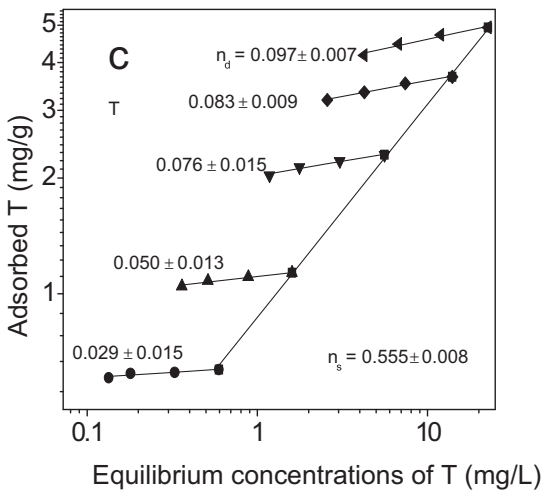

Fig. 4. Desorption of STZ and T from peat in the absence of metals (a) and in the presence of $1.0 \mathrm{mM} \mathrm{Cu}(\mathrm{b})$ or $1.0 \mathrm{mM} \mathrm{Al}(\mathrm{c})(n=3)$. 
Table 1

Freundlich parameters and desorption hysteresis coefficients ${ }^{\mathrm{a}}$ of STZ and T from peat.

\begin{tabular}{|c|c|c|c|c|c|c|c|}
\hline & \multirow[t]{2}{*}{$C_{\mathrm{i}}^{\mathrm{b}}(\mathrm{mg} / \mathrm{L})$} & \multicolumn{2}{|c|}{$\begin{array}{l}\text { In the absence of } \\
\text { mental ions }\end{array}$} & \multicolumn{2}{|l|}{$1.0 \mathrm{mM} \mathrm{Cu}$} & \multicolumn{2}{|l|}{$1.0 \mathrm{mM} \mathrm{Al}$} \\
\hline & & $n_{\text {desorption }}$ & HI & $n_{\text {desorption }}$ & HI & $n_{\text {desorption }}$ & $\mathrm{HI}$ \\
\hline \multirow[t]{5}{*}{ STZ } & 2.5 & 0.19 & 0.25 & 0.12 & 0.16 & 0.19 & 0.24 \\
\hline & 5.0 & 0.24 & 0.31 & 0.16 & 0.22 & 0.26 & 0.33 \\
\hline & 12.5 & 0.33 & 0.42 & 0.20 & 0.27 & 0.32 & 0.41 \\
\hline & 25.0 & 0.35 & 0.45 & 0.23 & 0.32 & 0.35 & 0.44 \\
\hline & 37.5 & 0.37 & 0.47 & 0.25 & 0.35 & 0.43 & 0.49 \\
\hline \multirow[t]{5}{*}{$\mathrm{T}$} & 2.5 & 0.042 & 0.081 & 0.023 & 0.052 & 0.029 & 0.045 \\
\hline & 5.0 & 0.066 & 0.13 & 0.056 & 0.11 & 0.050 & 0.090 \\
\hline & 12.5 & 0.13 & 0.25 & 0.074 & 0.15 & 0.076 & 0.14 \\
\hline & 25.0 & 0.14 & 0.28 & 0.093 & 0.18 & 0.083 & 0.15 \\
\hline & 37.5 & 0.15 & 0.30 & 0.11 & 0.21 & 0.097 & 0.17 \\
\hline
\end{tabular}

a Desorption hysteresis coefficient $\mathrm{HI}=n_{\text {des }} / n_{\text {ads. }}$.

b $C_{\mathrm{i}}$, initial concentration.

the prolonged adsorption equilibrium time of $\mathrm{T}$ on peat and soil in the presence of $\mathrm{Cu}$ and $\mathrm{Al}$.

Since desorption behavior can provide additional information on pore-filling effect, desorption of STZ and T from peat in the absence and presence of $\mathrm{Cu}$ and $\mathrm{Al}$ were examined (Fig. 4). The Freundlich desorption parameters are shown in Table 1. Desorption hysteresis coefficient (HI) of 1 means no desorption hysteresis, and the smaller HI corresponds to the greater degree of hysteresis (Yuan and Xing, 2001; Wang et al., 2009). In all cases, desorption of STZ and $\mathrm{T}$ was hysteretic, and desorption increased from low to high concentrations for both antibiotics as shown by the HI values (Table 1). The trend of increased desorption with increasing STZ and $\mathrm{T}$ concentrations can be explained by the limited number of high energy binding sites or soil pores available. At low concentrations, a large percentage of STZ and T bound to the high energy sites or filled these pores, resulting in decreased desorption. Increasing both antibiotics concentrations, more antibiotics molecules occupied low energy binding sites or adsorbed on external surface, which can be more readily desorbed (Wang et al., 2009).

The effects of $\mathrm{Cu}$ and $\mathrm{Al}$ on STZ and T desorption are also investigated. It was found that the HI values of STZ at each concentration were independent on the adsorption of $\mathrm{Al}$, while decreased with the adsorption of $\mathrm{Cu}$ (Table 1). This was because a portion of STZ was adsorbed on peat as $\mathrm{Cu}-\mathrm{STZ}$ complexes and/or through a $\mathrm{Cu}$ bridge, which is more difficult to be desorbed than that of sole STZ. For T, the adsorption of $\mathrm{Cu}$ and Al significantly decreased desorption of $\mathrm{T}$ (compare $\mathrm{HI}$ values in Table 1). As described above, the presence of $\mathrm{Cu}$ and $\mathrm{Al}$ decreased the pore size of peat and soil, which made the adsorbed $\mathrm{T}$ in soil pores more difficult to be desorbed than that in the absence of $\mathrm{Cu}$ or Al due to structural deformation of peat and soil pores. This was also further verified that the changes of soil structures played a key role in the adsorption of organic contaminants, especially for large-sized contaminants.

\section{Conclusions}

In view of the foregoing study, the presence of $\mathrm{Cu}$ suppressed STZ adsorption at $\mathrm{pH}<5.0$ due to the electrostatic competition between $\mathrm{STZ}^{+}$and $\mathrm{Cu}^{2+}$ for the same negatively charged adsorption sites on peat and soil. In contrast, $\mathrm{Cu}$ increased STZ adsorption remarkably on peat and soil at $\mathrm{pH}>5.0$. This was mainly attributed to the formation of STZ-Cu complexes and/or Cu bridge. As for Al, it decreased STZ adsorption at $\mathrm{pH}<6.0$, and exerted slight effect on the STZ adsorption at $>6.0$. It is due to that the prevailing species of $\mathrm{Al}$ at $\mathrm{pH}>6.0$ were $\mathrm{Al}(\mathrm{OH})_{4}^{-}$and a small amount of $\mathrm{Al}(\mathrm{OH})_{3}$ precipitate, which had little effect on $\mathrm{STZ}^{-}$adsorption on peat and soil.
Compared to STZ, Cu/Al decreased T adsorption on peat and soil over the examined $\mathrm{pH}$ range. Several possible mechanisms may be responsible for the suppressed adsorption of $\mathrm{T}$ in the presence of $\mathrm{Cu} / \mathrm{Al}$ are as following: (1) competition between cationic $\mathrm{Cu} / \mathrm{Al}$ and $\mathrm{T}^{+}$for the same adsorption sites on peat and soil; (2) the adsorption of cationic $\mathrm{Cu}$ and $\mathrm{Al}$ made the surfaces of both peat and soil less negatively charged and was unfavorable for the adsorption of $\mathrm{T}^{+}$ through electrostatic attraction; (3) $\mathrm{Cu}$ and $\mathrm{Al}$ decreased the pore size of peat and soil, thus retarded the diffusion of large-sized $\mathrm{T}$ to these pores.

\section{Acknowledgment}

This work was funded by National Natural Science Foundation of China (grant number: 41071308) and National Key Basic Research Program of China (973 Program) (grant number: 2014CB441102).

\section{Appendix A. Supplementary material}

Supplementary material related to this article can be found at http://dx.doi.org/10.1016/j.envpol.2013.09.038.

\section{References}

Boxall, A.B.A., Blackwell, P., Cavallo, R., Kay, P., Tolls, J., 2002. The sorption and transport of sulphonamide antibiotic in soil systems. Toxicol. Lett. 131, 19-28.

Frisch, M.J., Trucks, G.W., Schlegel, H.B., Scuseria, G.E., Robb, M.A., Cheeseman, J.R., et al., 1998. Gaussian 98. Gaussian, Inc., Pittsburgh, PA.

Golet, E.M., Alder, A.C., Giger, W., 2002. Environmental exposure and risk assessment of fluoroquinolone antibacterial agents in wastewater and river water of the Gatt Valley watershed, Switzerland. Environ. Sci. Technol. 36, 3645-3651.

Gu, C., Karthikeyan, K.G., 2005. Sorption of the antimicrobial ciprofloxacin to aluminum and iron hydrous oxides. Environ. Sci. Technol. 39, 9166-9173.

Heberer, T., 2002. Tracking persistent pharmaceutical residues from municipal sewage to drinking water. J. Hydrol. 266, 175-189.

Hou, T., Xu, R.K., Tivari, D., Zhao, A.Z., 2007. Interaction between electrical double layers of soil colloids and Fe/Al oxides in suspensions. J. Colloid Interf. Sci. 310, 670-674.

Ji, L.L., Liu, F.L., Xu, Z.Y., Zheng, S.R., Zhu, D.Q. 2010. Adsorption of pharmaceutical antibiotics on template-synthesized ordered micro- and mesoporous carbons. Environ. Sci. Technol. 44, 3116-3122.

Kahle, M., Stamm, C., 2007. Sorption of the veterinary antimicrobial sulfathiazole to organic materials of different origin. Environ. Sci. Technol. 41, 132-138.

Kolpin, D.W., Furlong, E.T., Meyer, M.T., Thurman, E.M., Zaygg, S.D., Barber, L.B., Buxton, H.T., 2002. Pharmaceuticals, hormones, and other organic wastewater contaminants in U.S. streams, 1999-2000: a national reconnaissance. Environ. Sci. Technol. 36, 1202-1211.

Kolz, A.C., Ong, S.K., Moorman, T.B., 2005. Sorption of tylosin onto swine manure. Chemosphere 60, 284-289.

Lu, Y.F., Pignatello, J.J., 2004. Sorption of apolar aromatic compounds to soil humic acid particles affected by aluminum(III) iron crosslinking. J. Environ. Qual. 33, 1314-1321.

Luo, L., Zhang, S.Z., Ma, Y.B., Christie, P., Huang, H.L., 2008. Facilitationg effects of metal cations on phenanthrene sorption in soils. Environ. Sci. Technol. 42, 2414-2419.

Nakagawa, K., Namba, A., Mukai, S.R., Tamon, H., Ariyadejwanich, P., Tanthapanichakoon, W. 2004. Adsorption of phenol and reactive dye form aqueous solution on activated carbons derived from solid wastes. Water Res. 38, 1791-1798.

Nelson, D., Sommers, L., 1996. In: Methods of Soil Analysis; Part 3, Chemical Methods. Soil Science Society Book Series, vol. 5. American Society of Agronomy, Madison, WI, pp. 961-1010.

Nowara, A., Burhenne, J., Spiteller, M., 1997. Binding of fluoroquinolone carboxylic acid derivatives to clay minerals. J. Agric. Food Chem. 45, 1459-1463.

Pan, B., Qiu, M.Y., Wu, M., Zhang, D., Peng, H.B., Wu, D., 2012. The opposite impacts of $\mathrm{Cu}$ and $\mathrm{Mg}$ cations on dissolved organic matter-ofloxacin interaction. Environ. Pollut. 161, 76-82.

Pei, Z.G., Shan, X.Q., Wen, B., Zhang, S.Z., Liu, T., Xie, Y.N., Khan, S.U., 2006. Effect of lead on the sorption of 2,4,6-trichlorophenol on soil and peat. Environ. Toxicol. Chem. 25, 2584-2592.

Pei, Z.G., Shan, X.Q., Zhang, S.Z., Kong, J.J., Wen, B., Zhang, J., Zheng, L.R., Xie, Y.N., Janssens, K., 2011. Insight to ternary complexes of co-adsorption of norfloxacin and $\mathrm{Cu}(\mathrm{II})$ onto montmorillonite at different using EXAFS. J. Hazard. Mater. 186 $842-848$.

Qin, F., Shan, X.Q., Wen, B., 2004. Effects of low-molecular-weight organic acids and residence time on desorption of $\mathrm{Cu}, \mathrm{Cd}$, and $\mathrm{Pb}$ from soils. Chemosphere 57, $253-263$. 
Sarmah, A.K., Meyer, M.T., Boxall, A.B.A., 2006. A global perspective in the use, sales, exposure pathways, occurrence, fate and effects of veterinary antibiotics (VAs) in the environment. Chemosphere 65, 725-759.

Schmitt, H., Stoob, K., Hamscher, G., Smit, E., Seinen, W., 2006. Tetracyclines and tetracycline resistance in agricultural soils: microcosm and field studies. Microb. Ecol. 51, 267-276.

Sumner, M., Miller, W., 1996. In: Methods of Soil Analysis; Part 3, Chemical Methods. Soil Science Society Book Series, vol. 5. American Society of Agronomy, Madison, WI, pp. 1201-1230.

Ter Laak, T.L., Gebbink, W.A., Tolls, J., 2006. The effect of pH and ionic strength on the sorption of sulfachloropyridazine, tylosin, and oxytetracycline to soil. Environ. Toxicol. Chem. 25, 904-911.

Thiele-Bruhn, S., Seibicke, T., Schulten, H.R., Leinweber, P., 2004. Sorption of sulfonamide pharmaceutical antibiotics on whole soils and particle-size fractions. J. Environ. Qual. 33, 1331-1342.

Tolls, J., 2001. Sorption of veterinary pharmaceuticals in soils: a review. Environ. Sci. Technol. 35, 3397-3406.

Trivedi, P., Vasudevan, D., 2007. Spectroscopic investigation of ciprofloxacin speciation at the goethite-water interface. Environ. Sci. Technol. 41, 3153-3158.

Ugochukwu, N., Ebong, E., Uzoma, O., Fu, Q.L., Huang, L., Hu, H.Q., 2011. Impacts of inorganic ions, and temperature on lead adsorption onto variable charge soils.
In: International Conference on Chemical, Biological and Environment Science, Bangkok Dec.

Wang, X.L., Yang, K., Tao, S., Xing, B.S., 2007. Sorption of aromatic organic contaminants by biopolymers: effects of $\mathrm{pH}$, copper(II) complexation, and cellulose coating. Environ. Sci. Technol. 41, 185-191.

Wang, Y.J., Jin, D.A., Sun, R.J., Zhu, H.W., Zhou, D.M., 2008. Adsorption and cosorption of tetracycline and copper(II) on montmorillonite as affected by solution pH. Environ. Sci. Technol. 42, 3254-3259.

Wang, Y.S., Shan, X.Q., Feng, M.H., Chen, G.C., Pei, Z.G., Wen, B., Liu, T., Xie, Y.N., Owens, G., 2009. Effects of copper, lead, and cadmium on the sorption of 2,4,6trichlorophenol onto and desorption from wheat ash and two commercial humic acids. Environ. Sci. Technol. 43, 5726-5731.

Wang, Z.Y, Yu, X.D, Pan, B, Xing, B.S, 2010. Norfloxacin sorption and its thermodynamics on surface-modified carbon nanotubes. Environ. Sci. Technol. 44, 978-984. Yuan, G.S., Xing, B.S., 2001. Effects of metal cations on sorption and desorption of organic compounds in humic acids. Soil Sci. 166, 107-115.

Zhou, J.L., 2006. Sorption and remobilization behavior of 4-tert-octylphenol in aquatic systems. Environ. Sci. Technol. 40, 2225-2234.

Zoritaa, S., MÅrtensson, L., Mathiasson, L., 2009. Occurrence and removal of pharmaceuticals in a municipal sewage treatment system in the south of Sweden. Sci. Total Environ. 407, 2760-2770. 